Journal of Sustainability Business Research (JSBR)

Vol-1,Issue-1,Desember (JSBR)

E-ISSN: 2746-8607

http://jurnal.unipasby.ac.id/index.php/jsbr

\title{
PENGARUH PENERAPAM SISTEM INFORMASI AKUNTANSI TERHADAP KINERJA KARYAWAN DENGAN INTEGRITAS KARYAWAN SEBAGAI VARIABEL PEMODERASI PADA CV PRAKARSA BUANA SENTOSA \\ Ganesha Ade Kusumawardhani ${ }^{1}$, Teguh Purwanto ${ }^{2}$ \\ Universitas PGRI Adi Buana Surabaya ${ }^{1,2}$ \\ ganeahaade@gmail.com, teguhpwt@gmail.com
}

\begin{abstract}
This observation has the intention to test and unserstand the evidence of wheather the employee's performance is influenced by the accounting information system, the accounting information system is influenced by employee integrity, whether the employee's performance on CV Prakarsa Buana Sentosa is influenced by employee integrity so that it can strengthen the effects of accounting information systems simultaneously. In this study used 41 employee specimens utilizing slovin theory. The measurement scale uses a likert scale. The translation method in this observation uses validity, reliability, classic assumptions, and multiple linear regression methods. The results of observations by distributing questionnaires to 41 employess of CV Prakarsa Buana Sentosa initiative concicting of 7 sales division employees, 7 purchase division employees, 8 marketing division employees, 2 manager division employees, 9 warehouse division employees, and 8 shipping division employees. Then it can be concluded that the employee's performance is influenced by the accounting information system simultaneously, while the employee's intensity is not able to moderate the relationship between the employee's performance towards the accounting information system.
\end{abstract}

Keyword: Accounting Informasition Systems, Employee Performance, Integrity Employee

\section{PENDAHULUAN}

Pesatnya pertambahan technologi di era globalisasi kini sudah menyampaikan dampak yang positif di beragam macam aspek sosial sehingga mempengaruhi dunia usaha, di dalam operasional perusahaan kebanyakan amat membutuhkan teknologi seperti teknologi informasi.

Sistem informasi akntansi pula termasuk kedalam IT (Informatiion Technologi) untuk menyajikan sebuah data perusahaan yag pantas atas kepentingan menajemen internal perusahan ataupun beragam bagian external perusahaan.Informasi memang sagatlah penting, karena informasi sebagai bagian pembatas ketika pengutipan suatu ketetapan. Secara umum informasi yang obyektif bisa mendukung efesiensi operasional perusahan.

Dalam sebuah perusahaan intigritas mempunyai arti kesepakatan yang bekerja atas kode etik dan kearifan di dalam instansi. Intigritas menjadi kualitas yang melandasi tumbuhnya kepercayaan pimpinan terhadap karyawannya.

Bagi mewujudkan kemampuan karyawan yang maksimal maka perusahan bisa memperkirakan hasil profesi pekerjaan masing - masing pegawai atas standart yng elah di buat bagi instansi, atas suatu kesuksesan perusahaan di pengaruhi atas kemampuan pegawai.

\section{METODE}

Observasi ini termasuk kesalam penelitian kuantitatif yang berupa asosiatip. Populasi dalam observasi ini ialah seluruh pegawai CV Prakarsa Buana Sentosa, sampel menggunakan teori slovin dengan tingkat kesalahan $5 \%$ dan diperoleh sampel 44 pegawai. Skala pengukuran menggunakan skala likert, metode pengukuran data memakai regresi liniear berganda, tes asumsi klasik, tes F dan tes T, dan di bantu oleh sofware SPSS. (Statisticial Package For Social Scentes)

\section{HASIL}

Sebelum melakukan pengujian hipotesis pada penelitian ini di lakukan pengujian instrumen terlebih dahulu guna mengetahui variable yang diteliti valid dan relibel.

Uji Validitas 


\section{Journal of Sustainability Business Research (JSBR)}

Vol-1,Issue-1,Desember (JSBR)

E-ISSN: 2746-8607

http://jurnal.unipasby.ac.id/index.php/jsbr

observasi ini untuk mengukur validitas sebuah variable dengan korelasi diatas ,3. jika nilai kritis dibawah ,3. tidak akurat.

Adapun uji validitas kuisioner variable yang diteliti.

Tabel. 1

Validity test.

$\left(X_{1}, X_{2} X_{3}\right)$

\begin{tabular}{|c|c|}
\hline \multicolumn{2}{|c|}{$\left(X_{1} . X_{2}, X_{3}\right)$} \\
\hline Perny & Korelasi \\
\hline 1 &, 537 \\
\hline 2 & ,694 \\
\hline 3 & ,774 \\
\hline 4 & ,546 \\
\hline 5 & ,830 \\
\hline 6 & ,713 \\
\hline 7 & ,657 \\
\hline 8 & ,714 \\
\hline 9 & ,771 \\
\hline 10 & ,495 \\
\hline 11 & ,563 \\
\hline 1 & ,870 \\
\hline 2 & ,866 \\
\hline 3 & ,862 \\
\hline 1 & ,714 \\
\hline 2 & ,777 \\
\hline 3 & ,726 \\
\hline 4 & ,821 \\
\hline 5 & ,728 \\
\hline & \\
\hline
\end{tabular}

\section{Uji Realibilitas}

Percobaan dilakukan perlu mengetes konsistensi suatu variable, suatu variable dikatakan relibel jika memberikan skala alphacronbach makin besar dari nol koma enam puluh. Berikut hasil tes realibilitas disajikan di tabel ini.

Percobaan dilakukan perlu mengetes konsistensi suatu variable, suatu variable dikatakan relibel jika memberikan skala alphacronbach makin besar dari nol koma enam puluh. Berikut hasil tes realibilitas disajikan di tabel ini.

Tabel. 2 
Journal of Sustainability Business Research (JSBR)

Vol-1,Issue-1,Desember (JSBR)

E-ISSN: 2746-8607

http://jurnal.unipasby.ac.id/index.php/jsbr

\begin{tabular}{|c|c|c|}
\multicolumn{3}{|c}{ Reability Test } \\
\hline (V) & $\begin{array}{r}\text { Cronbach } \\
\text { alpha }\end{array}$ & $\begin{array}{c}\text { Batas } \\
\text { Terendah }\end{array}$ \\
\hline $\mathrm{X}_{1}$ &, 871 &, 60 \\
\hline $\mathrm{X}_{2}$ &, 832 &, 60 \\
\hline $\mathrm{Y}$ &, 807 &, 60 \\
\hline
\end{tabular}

Percobaan hipotetis memerlukan analisa regesi liniear berganda, analisa tes asumsi klasik yng terbagi dari tes normalitas, tes multikolinearitas, tes heterokedastisitas, tes auto kolerasi dan tes $\mathrm{T}$, tes F. Observasi lolos dalam pengujian analisis uji asumsi klasik atas persyarat dan keputusan yang sudah diatur bagi masing - masing analisis.

Untuk hasil persamaan regresi liner berganda sebagai berkut :

Persamaan $1 \mathrm{X}_{1}$. Terhadap $\mathrm{Y}$.

Tabel. 3

\begin{tabular}{rrrrrr}
\multicolumn{5}{c}{ Regression (SIA) terhadap Y. } \\
\hline Variable & $\begin{array}{c}\text { Unstandardizzed } \\
\text { coefisiens }\end{array}$ & Beta & $\mathrm{t}$ & Sig \\
Constant & 11,483 & 2,333 & & 4,922 &, 000 \\
\hline SIA $\left(\mathrm{X}_{1}\right)$ &, 281 &, 051 &, 567 & 4,303 &, 000 \\
\hline
\end{tabular}

$$
Y=11,483+, 218 X_{1}+e
$$

Kesimpulan dari hasil tersebut ialah jika nilai konstanta sebesar 11,483 dan Sistem informasi bernilai nol (0) bahwa, kinerja karyawan, akan sebanyak 11,483, dan jika nilai satuan sistem informasi akuntansi berubah satu bahwa bisa merubah satu satuan kinerja karyawan ,218.

Koefisien korelasi sistem informasi akuntansi atas kinerja karyawan sebanyak ,567 sehingga mempunyai hubungan yang sedang.

Persamaan 2. X. Memoderasi. X $X_{1}$ Terhadap Y.

Tabel. 4

Regresi Moderating

\begin{tabular}{crrrrr}
\hline Variable & \multicolumn{2}{c}{$\begin{array}{c}\text { Unstandar } \\
\text { dizzed } \\
\text { coefisiens }\end{array}$} & $\begin{array}{c}\text { B } \\
\text { et }\end{array}$ & T & Sig \\
Constant &, 5 & 2,820 & &, 02 &, 98 \\
& 21 & & & 5 & 0 \\
\hline SIA $\left(X_{1}\right)$ &, 3 &, 462 &, 9 &, 81 &, 42 \\
& 77 & & 82 & 5 & 0 \\
\hline Intigritas &, 9 & 1,617 &, 7 &, 60 &, 55 \\
Karyawan & 76 & & 08 & 3 & 0 \\
\hline SIA $\left(X_{1}\right)^{*}$ & - &, 035 & - & - &, 67 \\
Intigritas &, 0 & &, 8 &, 42 & 4 \\
& 15 & & 50 & 4 & \\
\hline
\end{tabular}




\section{Journal of Sustainability Business Research (JSBR) \\ Vol-1,Issue-1,Desember (JSBR)}

E-ISSN: 2746-8607

http://jurnal.unipasby.ac.id/index.php/jsbr

$$
Y .=, 521+, 377 X_{1}+, 976 X_{2}+\left(-, 015 X_{1} X_{2}\right)+E
$$

Kesimpulannya ialah jika sistem informasi akuntansi atas integrtas karyaean menjadi variable moderation sepadan dengan (0) maka kinerja karyawan ,521 satuan. Dan jika nilai kofiien sistem informasi akuntansi berpengaruh serah atas kinerja karyawan ,377 dan apabila berubah satu bahwa kinerja karyawan ,377 satuan. Dan jik skala koefisien intigritas karyawan berpengaruh searh dengan kinerja karyawan ,976 dan jika berubah satu bahwa kinerja karyawan ,976 satuan.

Koefisien korelasi sistem informasi akuntansi, intigritas karyawan, kinerja karyawan sebesar ,602 yaitu mempunyai hubungan yang kuat.

\section{TES T}

Akan memperkirakan pengaruh maing - masing variable sebagai parsial, tingkat signifikan pada uji t adalah dibawah nol koma lima / lima persen menyatakan suatu mempengaruhi variable

Tabel. 5

T. Parsial

Persamaan $1\left(X_{1}\right.$ tehadap $\left.Y\right)$

Variable Unstandardizzed Beta $\mathrm{T}$ Sig
coefisiens

\begin{tabular}{rrrrrr} 
Constant & 11,483 & 2,333 & & 4,922 &, 000 \\
\hline SIA $\left(X_{1}\right)$ &, 281 &, 051 &, 567 & 4,303 &, 000
\end{tabular}

dapat kita ketahui bahwa Sistem Informasi Akuntansi $\left(X_{1}\right)$ memberikan thitung sebanyak 4,922 dengan tingkat sig ,000 <,05 batas variable Sistim Informasi Akntansi $\left(X_{1}\right)$ berakibat secara parsial kepada Kinerja Karyawan (Y).

Tabel. 6

T. Parsial

Persamaan 2 Moderasi

\begin{tabular}{crrrrr}
\hline Variable & \multicolumn{2}{c}{$\begin{array}{c}\text { Unstandar } \\
\text { dizzed } \\
\text { coefisiens }\end{array}$} & $\begin{array}{c}\text { B } \\
\text { et }\end{array}$ & T & Sig \\
\hline Constant &, 5 & 2,820 & &, 02 &, 98 \\
& 21 & & & 5 & 0 \\
\hline SIA $\left(\mathrm{X}_{1}\right)$ &, 3 &, 462 &, 9 &, 81 &, 42 \\
& 77 & & 82 & 5 & 0 \\
\hline Intigritas &, 9 & 1,617 &, 7 &, 60 &, 55 \\
Karyawan & 76 & & 08 & 3 & 0 \\
\hline SIA $\left(\mathrm{X}_{1}\right)^{*}$ & - &, 035 & - & - &, 67 \\
Intigritas &, 0 & &, 8 &, 42 & 4 \\
& 15 & & 50 & 4 & \\
\hline
\end{tabular}

dapat kita ketahui bahwa Sistem Informasi Akuntansi $\left(X_{1}\right)$ memberikan thitung ,815 serta tingkat sig ,420 $>$,05 sehingga variable Sistem Informsi Akuntansi. $\left(X_{1}\right)$ tidak berakibat selaku parsial akibat Kinerja Karyawan (Y).

Intigritas Karyawan $\left(\mathrm{X}_{2}\right)$ memberikan $t_{\text {hitung }}, 603$ atas sig ,550 > ,05 sehingga Kinerja Karyawan $(\mathrm{Y})$ tidak berakibat parsial oleh intigritas karyawan $\left(X_{2}\right)$.

Sistem Informasi Akuntansi $\left(X_{1}\right)^{*}$ Intigritas Karyawan $\left(X_{2}\right)$ sebagai Variable moderasi memberikan thitung ,- 424 atas taraf sig ,674 >,05 bisa dianggap variable intigritas karyawan tidak bisa mempengaruhi 


\section{Journal of Sustainability Business Research (JSBR) \\ Vol-1,Issue-1,Desember (JSBR) \\ E-ISSN: 2746-8607}

http://jurnal.unipasby.ac.id/index.php/jsbr

moderasi hubungan SIA terhadap kinerja karyawan di karenakan suatu perusahan CV Prakarsa Buana Sentosa tanpa intigritas karyawan kinerja karyawan pun bisa berjalan dengan lancar.

UJI F

Pada dasarnya tes $\mathrm{F}$ menerangkan seluruh variable memiliki akibat sebagai bergabungan atas patokan pemungutan hasil seperti ini :

1. Jika perhitungan $\mathrm{F}$ makin besar maka HO. Tidak diterima atas level kepercayan liam persen atau 0.05 atas istilah lain kami membenarkan hipotessis alternatif, yng meyatakan seluruh variable indipenden selaku bersama - sama dan releven akibat variable dependen.

2. analogi perhitungan $F$ hsil estimasi atas $F$ berdasarkan daftar. Jika perhitungan $F_{\text {hitung }}$ makin tinggi dari pada perhitungan $\mathrm{F}_{\text {tabel, }}$ bahwa $\mathrm{Ho}$ di tidak diterima dan Ha diterima.

Tabel. 7

F. Simultan

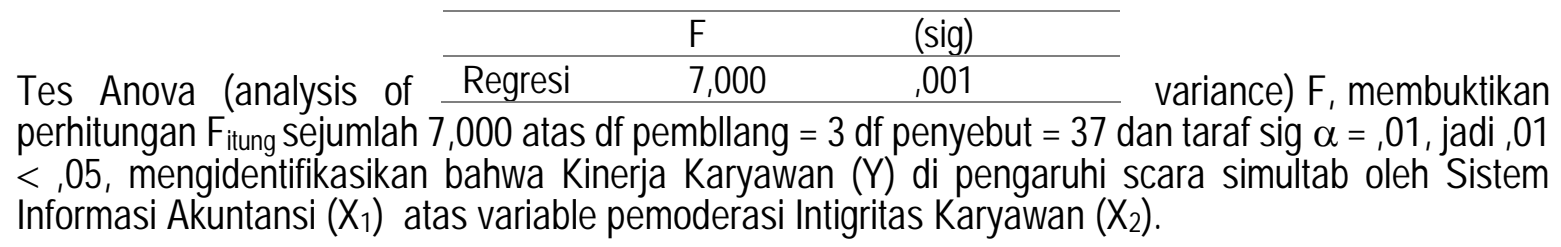

SIMPULAN

Berdasarkan analisi yang telah dilakukan menggunaka analisa regrsi iniear berganda atas asistensi SPSS hingga bisa diambil jawaban. implementasi sistim informasi akuintansi berakibat positif dan releven kepada kemampuan karyawan. Keadaan ini dikarenakan implementasi sistem informasi akuintansi atas CV Prakarsa Buana Sentosa di Surabaya akan mempercepat dan memudahkan penanganan pekerjaan yang dikerjakan oleh perorangan terhadap perusahaan terhoprmat. Dalam penelitian ini kinerja karyawan tak dipengaruhi oleh intigritas karyewan. Artinya bahwa intigritas atas CV Prakarsa Buana Sentosa tidak seberapa berakibat kepada kinwerja karyaswan hingga dapat disimpulkan pada observasi ini intigritas karyawan tidak bisa moderasi hubungan SIA Sistem Informasi Akuntansi kepada Kinertja Karyawan.

\section{IMPLIKASI}

Implikasi hasil penelitian ini adalah sebagai refreansi dan tambahan teori untuk perusahaan, dengan adanya sistimm informasi akuntansi mampu mengamalkan akibat postif kepada perusahaan. Hal ini dapat mendukung pekerja seraya menuntaskan tugasnya cermat cepat waktu dan akurat kebenarannya, dan dapat mendukung manager untuk pemungutan suatu kepastian atas adanya sistim informasi akunmtansi.

\section{KETERBATASAN PENELITIAN}

Terbatasan observasi ini adalah :

1. Sistim informasi yang digunakan oleh perusahaan masih belum maksimal dan akurat, dimana sistim informasinya masih sering mengalami salah posting.

2. Kinerja karyawan pada perusahaan belum terlalu paham dengan pengaruh adanya sistim informasi akuntansi.

\section{DAFTAR PUSTAKA}




\section{Journal of Sustainability Business Research (JSBR) Vol-1,Issue-1,Desember (JSBR) \\ E-ISSN: 2746-8607}

http://jurnal.unipasby.ac.id/index.php/jsbr

Andi. 2017. Sistem Informasi Akuntansi. Yogyakarta : TMBOOK.

Anwar, P. M. 2005. Evaluasi Kinerja Sumber Daya Manusia. Bandung : Refika Aditama.

Azar, Susanto. 2008. Sistem Informasi Akuntansi. Bandung : Lingga Jaya

Damayanti, Deka. 2018. Pengaruh Pengendalian Internal, Sistem Informasi Akuntansi, Dan Motivasi Kerja Terhadap Kinerja Karyawan Dengan Kapasitas Sumber Daya Manusia Sebagai Vriabel Moderating. Skripsi. Universutas Lampung.

Dewi , P .S. 2017. Pengaruh Sistem Informasi Akuntansi Dan Budaya Organisasi Terhadap Kinerja Organisasi Hotel Di Kabupaen Buleleng. E-jurnal. Volume 7, Nomor 1, Universitas Pendidikan Ganesha.

Dita, M .A. 2016. Pengaruh Penerapan Sistem Informasi Akuntansi Terhadap Kinerja Karyawan Dengan Intigritas Karyawan Sebagai Variable Pemoderasi. E-jurnal. Volume 15, Nomor 1, ISSN : 2302-8556, Universitas Udayana.

Melasari, Ranti. 2017. Pengaruh Penerapan Sistem Informasi Akuntansi Terhadap Kinerja Karyawan Dengan Intigritas Karyawan Sebagai Variable Pemoderasi. Jurnal Akuntansi Keuangan. Volume 6, Nomor 1, ISSN :2089-6255, Universitas Islam Indragiri Tembilan.

Suhud, S .P. 2015. Pengaruh Penerapan Sistem Informasi Akuntansi Terhadap Kinerja Individu Pegawai Distro Di Kota Bandung. Skripsi. Universitas Diponegoro.

Sigilipu, steffi. 2013. Pengaruh Penerapan Informasi Akuntansi Manajemen. Jurnal Embal. Volume 1, Nomor 3 , ISSN : 2303-1174, Universitas Sam Ratulangi Manado. 
Journal of Sustainability Business Research (JSBR)

Vol-1,Issue-1,Desember (JSBR)

E-ISSN: 2746-8607

http://jurnal.unipasby.ac.id/index.php/jsbr 